\title{
BECOMING A SOCIALLY SENSITIVE DENTIST; A REVIEW OF SOME TRENDS*
}

\author{
By H. Barry Waldman, D.D.S., M.P.H.**
}

This paper has been prepared as a portion of a study

to investigate the status of students' sensitivity towards community life and to make recommendations for improving their sensitivity.

The dental profession traditionally has been concerned with the restoration, removal, and replacement of teeth and the care of their supporting tissues. While the principal focus continues to be the same, a more scientific orientation has evolved in which the entire patient became the focus, and then changed to an interest in the patient's community.

While the dentist of the past was technically trained and biologically oriented, today's practitioners are exhorted to be "technically competent, biologically knowledgeable, and socially sensitive." 25 To speak of dentistry today as a single career is misleading because the profession encompasses many types of careers, each essential to the total health of a complex society.

The curriculums of schools of dentistry have been revised; personnel from disciplines, seemingly far removed from dentistry, have been added to faculties; and clinical experience now is provided in ghettos, nursing homes, and the rural countryside. Much is being inaugurated in an effort to create a new socially conscious dental practitioner.

The task of the report, about to be made, will be a consideration of the results to be expected from efforts to develop a new practitioner. The report will focus on (1) the applicant who seeks admission to the profession; (2) the process for selecting the proper student; and (3) the occupational socialization of the student during his education and training.

The approach, to be used, will not be a simple review of pertinent literature nor repetition of the exact words of a number of previous writers who have summarized surveys and studies, for example, Counsell, ${ }^{20}$ Evans, ${ }^{26}$ Douglass, ${ }^{23}$ and Smith. ${ }^{116}$ Instead an approach will be attempted to interpret the professional trends which these publications portray. Hopefully, such a review will help the reader to understand the results to anticipate from many changes in dental curriculums.

Counsell's ${ }^{20}$ review of the literature on the image of dentistry, and the factors responsible for this image, concludes that the dentist's self-image is determined to a great extent by his own notions of how he is perceived as a dentist. The dentist is interested in gaining approbation from those whom he values-from the public and fellow practitioners. The development of a perceived role, status, or image is an essential part then of occupational socialization that each student must undergo before he may be termed truly professional.

The dentist's specific role may be equated with, or be recognized for its inclusion of a set of correct cultural patterns. ${ }^{41}$ It is the sum of ways of behaving which are expected of an individual who occupies a particular position in society. ${ }^{8}$ The role, hence, possesses many ingredients of culture, personality, and customary reaction to situations ${ }^{11}$ which become one ingredient of a still more complex social system. Although any social system is the total of those ideal patterns that control the individual's behavior and the reaction

\footnotetext{
* Submitted as a report to a class in Medical Care Organization.

* Applicant for Ph.D. in Medical Care Organization, School of Public Health, The University of Michigan, Ann Arbor. Michigan, 48104 . Supported by National Institute of Health. Fellowship
No. 2-503-DH-35, 158, Division of Dental Health.
} 
between this individual and society, ${ }^{62}$ each individual will be much more concerned with his particular situation than with the total social pattern.

An individual, it is thought, does not behave in a random manner. His actions are those that are expected from an individual who occupies his particular social position. ${ }^{63}$ How a person learns these expectations and how well he performs them is a function of socialization.

Socialization, the process by which a culture is transmitted and individuals are fitted into an organized way of life, is life-long. ${ }^{12}$ While society views the process in terms of fitting the individual into a continuing system, the individual views it as fulfilling his potentialities for personal growth and development. Socialization, hence, regulates behavior, but since it also is essential for development of individual self awareness, it transmits culture and develops personality. Inevitably it produces a degree of conformity. Individuals, reared under similar circumstances, should tend to resemble each other in values, habits, and, to some extent, personality.

To understand the socialization of the dentist, one must understand the profession's goals clearly, specifically, the precise behaviors that the profession hopes to produce. Young and Zwemer ${ }^{130}$ conclude that social sensitivity affects, not only private practice, but any special function of participation in professional activity in which the dentist engages as a community responsibility.

Henry ${ }^{50}$ asserts that the goal is a socially conscious, community oriented, politically informed, civically active, and professionally competent practitioner. Zwemer et al., ${ }^{133}$ Clark, ${ }^{19}$ Calisti, $^{16}$ and many others $9,21,30,51,65,82,92,100,109,113,123,132$ accept this goal as an obligation. It is an obligation to provide an ideal health service, not to an exclusive clientele only, but to the entire community.

This demand for "community practitioners," however, has to be studied in its proper perspective. Not all dentists are going to be exactly alike. The strength of a profession may be assisted by its diversity more than by its sameness. The goal of community concern, hence. cannot be defined as a series of precise actions that each practitioner must perform. It is a pattern to which the practice of dentistry conforms widely.

Now that this view of the "community dentist" performing within a "community profession" has been stated, it is time to turn to one of the initial phases of the socialization of the dentist-the selection of applicants by the schools of dentistry. It may not be the first step in the process, because the determination of which is the initial step gets difficult. The first step may be the initial receipt of dental treatment by a young person. This young person likes the dental office, likes the kind of service that the dentist performs and likes the dentist as a person. The first step may be the high school student's desire to improve his social status and his decision that dentistry will afford this opportunity. Sometimes it may be the college advisor's suggestion that a young person's interests and talents would be served best in the practice of dentistry.

Socialization begins at many stages and at many times. The student decides on dentistry because of his perceptions of a profession in the cultural environment of his socicty. His aspirations and the way they affect socialization later should be the starting point of this paper's review.

\section{The Applicant}

The dental student has been characterized by many investigators as conservative, conforming, unconsciously aggressive, persistent, methodical, and somewhat rigid and inflexible, ${ }^{20}$ and with motives of upward mobility and financial betterment. ${ }^{54}$ Additional studies by Mann, ${ }^{70}$ Heist, ${ }^{47}$ Fredericks. ${ }^{33}$ and several others ${ }^{49,} 67,75,76,77$, $78,79,80,98,125$ serve to reinforce this profile of the dental student. More, ${ }^{75}$ in his exhaustive study of freshman dental students in 1958 , notes that any campaign to enlist 
more applicants in the study of dentistry cannot ignore symbolic or even direct appeals to the possible applicant's desire for social status and occupation prestige, for financial improvement and security, for the chance to make creative use of manual talent, and for the opportunity to give genuinely needed service to mankind.

Many of the writers indicate that a dental career is chosen by the student only after serious consideration and frustration in gaining access to other more prestigious professions-generally medicine. Povalko ${ }^{98}$ notes from his survey of predental students that none would find it impossible to change their choice of a future dental career.

The dental profession, specifically dental educators, have recognized the marked difference between the profession's official pronouncements and aspirations ${ }^{4}$ and the character and motives of the dental applicant and later the student. In an attempt to overcome these marked differences, departments of social and community dentistry have been developed in most schools of dentistry in this country. The prime concern of these departments seems to be a desire to provide students with the insight needed for leadership in the humane aspects of practice. Numerous dental educators, public health officials, and social scientists, in fact, ask departments of community dentistry to present community needs to dental students. ${ }^{5}, 10,16,22,24,37,39,42,44,45,53,57,58,63,65$, $84,87,89,95,105,113,119,121,128,131$

From this widespread interest one might expect prompt success. Young and Zwemer $^{130}$ think, however, even by the time a student starts to prepare for his professional career, his major personality characteristics, sense of values, and behavioral attitudes probably have been determined by his parents, prior schooling, and his peers. They state that the main factors in determining the extent to which the student will acquire the characteristics of social sensitivity is his nature at the time he enters dental school. They conclude that teachers need humility regarding the amount and type of change in personality that can be attained through a course in social dentistry.

\section{The Process of Selection}

To understand the nature of the student who enters a school of dentistry, one must understand the process by which students are selected from many applicants. The Council on Dental Education of the American Dental Association ${ }^{2}$ demands, as a minimum requirement for admission to an accredited school of dentistry, the completion of at least two ycars of college education in an accredited college of liberal arts and sciences. This qualification must include credits for one full year each in English, biology, physics, and inorganic chemistry, and one-half year's credit in organic chemistry. Although this requirement lists the basic demands of the Council, it states minimum requirements. Individual schools may demand a longer preprofessional requirement and additional courses.

In addition to the formal educational requirements, each applicant must complete successfully the Dental Aptitude Test. ${ }^{3}$ This exercise is a battery of tests designed to measure the applicant's ability to (1) read scientific information with comprehension, (2) demonstrate manual dexterity, (3) reason with numbers, manipulate numerical rclationships, and deal intelligently with quantitative material, (4) use and understand the meaning of words, (5) visualize the reconstruction of two and three dimensional patterns, (6) demonstrate knowledge of elementary biology and chemistry, and (7) apply principles and solve problems in biology, and chemistry. In 1963 a survey of opinion, attitude, and interest was added on an experimental basis, ${ }^{38}$ but was eliminated in 1965 . The scores achieved on the Test constitute an important criterion in the determination of an applicant's admission to a school of dentistry. Only the applicant's predental scholastic average and his grades in required courses are assigned more weight. ${ }^{70}$

Since schools of dentistry seem to measure only the future ability of the practitioner as anticipated in performance while in dental school, it may be assumed that the emphasis 
on the undergraduate's average in grades and his scores in the Test represent an effort to secure practitioners of high quality for the future. An extensive serics of studies has been conducted to corroborate the close predictive relationship that exists between each detail of the Test, the student's undergraduate average in grades, and his academic accomplishments in the school of dentistry. $18,28,34,49,59,68,69,91,107,127$ The analysis of the results of the Test has been completed section by section, subject by subject, and year by year over a period of time. All of the researchers, and probably most of the committees on admission, are satisfied with the results. The series of criteria utilized today by the Committees on admission predict the dental student's scholastic and clinical performance effectively.

A question may be raised, not regarding the qualities that the Test measures, but regarding those attributes or aptitudes that it does not measure. During the past 17 years, the dental profession has experienced a total reappraisal and redirection of its values. Dental practice has progressed to the consideration of the entire patient and, to some extent, while the Test continues to measure the same criteria.

During these intervening years a comprehensive literature has developed in relating dentistry to the behavioral and social sciences. ${ }^{28,55,60,103,104,106,108,115,126}$ Many writers admonish the dental profession to accept the reality of dentistry as a practical application of the social sciences. The American Association of Dental Schools states officially. for example, "to speak of dentistry as a single career is misleading." (1) Official statements by schools of dentistry recommend that the preprofessional student limit his courses in natural and physical science to those required-especially those students with less than three and four years of undergraduate education-and to devote the remaining hours to cultural subjects, such as philosophy, history, psychology, and classical humanities. $^{1}$

The schools of dentistry, on the other hand, still appear to screen their applicants on their technical attributes and knowledge of physical sciences. ${ }^{83}$ Upshaw, ${ }^{124}$ in 1960 , reports that most schools base admission of applicants on the Test, transcripts of previous academic records, letters of reference, and, in some instances, interviews. These tests, he notes, are all indirect or predictive criteria of the success that might be expected in the technical aspects of dental education and the skills and ability needed for a good practitioncr. The problem has appeared today to develop indirect instruments that can predict, not merely the grades in courses as formerly, but the level of competence and concern for the nontechnical aspects of the practice of dentistry. The attributes to be predicted now are those of the practitioner not the student. ${ }^{124}$

More specifically, Upshaw points out the need to define first the nontechnical aspects of dentistry and then to agree on the characteristics of good and bad performance of these activities: and, secondly, to achieve a decision to add these components on the assumption that the greater the number of positive attributes the better the practice. Is the good practitioner the one who meets a minimum requirement on each attribute, or are the attributes disjunctive, to the point that the possession of one attribute makes for difficulty in possessing some other attributes?

One year later, Forrest, ${ }^{31}$ writing in the same journal for the samc editorial staff, lists the criteria for selecting dental students that follow:

1. The applicant must have an aptitude for science as demonstrated by the predental record and the aptitude test:

2. The applicant must possess dimensional perception and digital dexterity;

3. The applicant must have the ability to read with understanding commensurate with the level of the dental curriculum;

4. The applicant must have emotional stability and maturity compatable with graduate study;

5. The applicant must possess the physical stamina required by a demanding schedule: 
6. The applicant must demonstrate financial security or support;

7. The applicant must have a health motivation and attitude toward study and the profession to enhance future success.

This list omits the social and behavioral aspects of the prospective practitioner but stresses his financial security, the results of his Test and his predental average in grades.

More recently Nedelsky ${ }^{83}$ reviewed the problem discussed at a workshop convened to study the dental curriculum of 1980 . He found that today's requirements for entrance to schools of dentistry effectively prevent students from obtaining a liberal education. The entering class must include, therefore, a number of students who put little value on a liberal education.

The continued contradiction between official pronouncements and actual policies of admission also has significant effects at the level of the undergraduate college upon the advisor for preprofessional students. Friedrick ${ }^{32}$ reports from his review of preprofessional guidance counselors that they possess little understanding of today's concept of dental education, the types of students who will make the most of the dental curriculum, and the kind of preprofessional program that the predental student should pursue. He also notes that there is little guidance for the predental student, because the usual practice is to refer the student to the announcement of a school of dentistry. For information on preprofessional requirements, the advisor tells the student to contact the school of his choice. The emphasis in effort by guidance committees seems to be to process students for medical schools. The dental school may be recommended to those students who major in science, but do not show adequate performance for admission to medical schools, or who have been turned down by schools of medicine. The committees do not observe the excessive competition experienced by schools of dentistry and do not place as much priority on dentistry. Most guidance counselors of preprofessional students are biologists, chemists, physicists, or at times, college physicians. Rarely are members of the behavioral and social sciences designated as preprofessional counselors.

Findings, such as those reviewed, account for a mere six percent of dental students who indicate that preprofessional counselors influenced their decision to study dentistry. ${ }^{14,96}$ To find out who influences students to seek admission to a school of dentistry, other sources were reviewed. More, ${ }^{75} \mathrm{Mann},{ }^{70}$ and others report that a family (or other) dentist was the most outstanding individual to influence the choice of a dental career. Often this decision is made during high school by which time an image of dentistry has been firmly established in the mind of the teenager. ${ }^{50,}{ }^{70,102}$ Gray's findings ${ }^{40}$ add interest because she reports that most high school seniors view dentistry as a less varied and less satisfying career than that of the physician and the teacher. Of added importance, few students think of the dentist as working with people, but rather as working with things.

It would seem natural, once having made the decision to seek admission to a school of dentistry, that the student would attempt to excell in those particular subjects and satisfy those particular requirements considered most important by committees on admission. Mann and Parkin ${ }^{71}$ reported that more than three quarters of dental school applicants viewed their grades in required courses (which are courses in natural and physical science with the exception of English) as the most important criteria to be considered by committees on admissions. Strachan ${ }^{120}$ states that this view of grades in the required courses is one of the most important criteria considered by committees on admissions, still was correct in 1968.

This view of trends in dental education found in the literature reviewed leads to the point of entrance to a school of dentistry. He and his fellow entering classmates have made their selection of dentistry because of varied and yet similar reasons. They also have been accepted for admission for varied and yet similar reasons. The student's professional socialization, in light of today's demands, will be the subject of the next section of this review. 


\section{The Process of Professional Socialization}

To review the problem of changes in the dental student that result from his experience in the school of dentistry, one must keep educational objectives in mind. According to Stanford, ${ }^{117}$ four possibilities are available:

1. Activity may go according to the pattern of an examination of students at the beginning and at the end of their experience which show that they have changed in desired ways and that these changes were produced by educational procedures deliberately undertaken:

2. Although no desired change was anticipated when change is probable, the change may be a loss of the desired qualities that the student once possessed, or the development of undesirable qualities:

3. Changes may develop in the right direction, but may have nothing to do with the educational policies and practices of the institution; and

4. Changes of a desired type may be noted at the time of graduation, but not be sufficiently stable to serve the individual throughout life.

The educational process and, in turn, the socialization, are not a simple pouring of matter into an empty container. The process of professional socialization is a complex interchange between the individual to be socialized, the methodology used to socialize him, and the goals of the process. Professional schools often deliberately set out to terrorize their students, and to put them through a long series of rigorous and humiliating disciplinary actions. Some such schools can be matched in this respect only by certain strict girl's boarding schools or some nurses' training program. ${ }^{118}$

Socialization is not only that which the student must absorb, but it is also the impact of the process itself. In his survey of the graduates of 1962, More ${ }^{81}$ observed in all dental schools, save one, a deliberate attempt to subordinate the student and to force him to undergo a trial by ordeal. O'Shea et al. ${ }^{88}$ also describe student antipathy toward members of the faculty.

The problems in student-faculty relationships may, in many ways, be found similar to the problems in industrial relationships. Etzioni ${ }^{27}$ summarizes the two theoretical postures of management-worker relationship as

1. an approach to human relationships which emphasizes the significance of interpersonal relationships between the subordinate and the members of the subordinate group that utilize understanding, harmony, and two way communication; and

2. the approach by way of structural determinants, that emphasize the significance of position and function, with concern for the economic, cultural, and other real differences between the worker (the student) and management (the faculty).

Though little material exists in the dental literature relevant to dental socialization as a total process, the medical literature furnishes references to this problem. The medical literature, hence, will be presented as a framework for some later development of dental analogy.

Heist ${ }^{48}$ notes that the medical student and the process of his education can be described by the most complete body of psychological measurements ever collected on individuals with such singular occupational interests.

Miller $^{73}$ and others $6,12,52,72$ speak of the relationship between the group of medical students and the faculty in terms of suspicion, distrust, and a passion by the student for anonymity. The passion for anonymity comes from a belief that one's progress less likely will be blocked if he remains essentially unidentified for four years.

Although few students who enter medical school fail to graduate, many appear to be preoccupied with a fear of not graduating. An analysis of the medical student's culture ${ }^{6}$ reveals that an organizing response comes first to the academic challenge through which a collective effort by students is made to meet the demands of the school; and, secondly, once organized, this culture becomes a moderating force for a wide range of behavior-a 
kind of collective response by peers, in a subordinate status to the stress that they perceive as originating in a stratum of superiors. This analysis, in many ways, seems to crystalize a problem of student-faculty relationship. Should the medical student (and the dental student) be accepted as a student-physician or simply as a student? What, in turn, is the effect of the educational approach upon this potential physician (and dentist)?

Newcomb $b^{85}$ in his study of Bennington College reported his view of the importance of the school in the making of, and the changing of social values. While there are many differences between Newcomb's earlier work and the studies by From ${ }^{35,36}$ and others in medicine ${ }^{7,17}$ and dentistry ${ }^{81}$ these investigators tend to confirm Newcomb's view of the effects of a school's environment and the methods of instruction on students.

While a student may begin medical (and dental) school with a humanitarian attitude, he probably will graduate with a far more cynical view of those about him, one characterized by the view that human conduct is motivated by self-interest. Although Becker ${ }^{7}$ concludes that this change in, or loss of idealism is a necessary part of growth and development, Bloom ${ }^{12}$ views this particular vent of medical education as dehumanizing the future physician through its subjugation of the student and the nearly total absence of teaching in the social sciences and humanities. Bloom points out that the major research in medical education since World War II has been centered around the doctor-patient relationship, the concept of comprehensive care, and attempts to develop a totally integrated curriculum. He expresses the view that only in recent years has there been any consideration of the total process of medical education and its effect upon the future practitioner. Levinson, ${ }^{61}$ in his analysis of Becker's report, ${ }^{6}$ establishes a model for professional socialization that is relevant to the medical (and dental) student. He includes: (1) the organization of an environment for socialization that utilizes such concrete situations as lectures, experiences in the laboratory, meetings of the staff, and dormitory living, along with indirect symbolic influences such as the country's culture, its social structure, the educational goals of the school, and professional ideology, (2) a study of a person who occupies the position of a student that examines the personality of the entering student, the meaning of the medical school (and dental school) for him, the gains he hopes to achieve, his ideological orientation, and his characteristic traits; (3) the mechanism of the socializing process as it evolves to engage the student in the life of the system, how problems of ambiguity and uncertainty arise from a profession that prides itself on its rationality and competence, and how problems arise when the student's technical knowledges fail to meet the demands of the faculty; and (4) the outcome of socialization as it is measured by psychological changes that arise from contact with the direct and indirect technics which are a part of the system of educating students.

Becker, ${ }^{8}$ in his report, examines the changes in personality of adult life, and describes the process of socialization as a combination of two outcomes: (1) a situational adjustment in which change becomes a direct function of change in situational requirements, and (2) commitment that develops a personal attachment to the specific activities and goals providing a basis for consistency and stability in the individual's behavior in different situations.

\section{The Tasks Ahead of the Schools of Dentistry}

The review completed of some aspects of the socialization of the medical student and theoretical conclusions of those who have studied professional socialization now will be used as a frame of reference from which to examine in more detail the efforts of schools of dentistry to develop socially sensitive dental practitioners for the future. Departments of social and community dentistry appear to have been assigned the task of transforming the conservative, conforming, unconsciously aggressive, persistent, and somewhat rigid or inflexible student ${ }^{120}$ motivated to move upward and gain financial betterment, ${ }^{52}$ into a socially sensitive practitioner-one who is capable of understanding and contributing to 
the needs of a changing social environment. Some pertinent discussions will be scanned.

Blackerby ${ }^{11}$ summarizes the concern of departments of social dentistry (1) to respond to the dentist's need for a greater sense of social responsibility and (2) to remove the major imbalance that currently exists between the technical and the social phases of the dental curriculum.

Striffler 122 notes, in the same publication on social dentistry, that social awareness cannot be gained by forced-feeding. The student cannot gain, nor can he comprehend, a notion of "otherness" a priori. He must learn by experience that demands doing. Hein ${ }^{123}$ agrees when he calls for programs in which the student must participate. The concept of doing, however, means different procedures at different institutions. At the University of Kentucky School of Dentistry, the communitylaboratory cxperience ${ }^{65,109}$ is utilized to get students living in rural communities and lcarning first-hand the problems precipitated by rural poverty. At Tufts University, ${ }^{74}$ the University of Missouri, ${ }^{84}$ Howard University, ${ }^{1{ }^{3}}$ and Western Reserve University, ${ }^{125}$ the needs of the chronically ill, the aged, and other handicapped persons assist the dental student to stand and sympathize. Sometimes teaching is such that the department of social dentistry varies from an enigma to a total waste of time $^{81}$ in student-opinion.

For a moment, hence, the methods, most often used by schools of dentistry to evaluate competency of students, have to be considered. Knapp ${ }^{57}$ states that the ability of students generally expressed in terms of performing a particular number of technical procedures for each clinical department, the concept of numbers purveys the cntire clinical curriculum of the student's training. In many ways the clinical patient becomes a secondary consideration in teaching. ${ }^{10}$ It is understandable then when the nonproductive course in community dentistry is designated as a waste of time. Each student has a quota of treatments that must be completed if he is to graduate.

Preparation to pass the examination of the state board of dentistry compounds the problem. Originally, the boards were developed to ensure that qualified persons only entered the profession. Some writers observe that they also become, the guide for the education of the student. ${ }^{57,70}$ Orientation for passing the boards' examinations forces schools to devote much time to training students to perform procedures which sometimes are of limited value in practice. ${ }^{70}$ The limited impact of departments of social dentistry in this sort of competition appears obvious.

Departments of social dentistry, aware of their competitive problems, promptly renamed their departments and redirected their efforts. Because the Department of Public Health or Public Health Dentistry sounds alien to the province of the private practitioner of dentistry, departments have experienced with is now the Department of Ecological Dentistry, ${ }^{37}$ Social Dentistry, ${ }^{10}$ and Preventive Dentistry and Community Health. ${ }^{129}$

The early collection of courses on community mental health, maternal and child health, environmental health, health education, and some other considerations of public health practice has been integrated and redirected to the particular interests of the dental practitioner. Departments of social dentistry employ psychologists, sociologists, epidemiologists, political scientists, lawyers, biostatisticians and a number of other full and part-time teachers of social and behavioral sciences. ${ }^{109}$ The content now includes such items as cthics, jurisprudence, public hcalth, psychology, sociology, civil defense, chronic illness and rehabilitation, management of practice, prevention, the history of dentistry, and the utilization of dental auxiliaries. Many new teaching aids and various approaches have been developed to assist in the presentation of today's ideas of dental public health. ${ }^{93,94}$ Of tremendous importance for growth and improve ment, efforts are being made by the departments of social dentistry to evaluate the effects of new approaches. $27.43,54,92$ 
Quarantelli, ${ }^{99}$ after a study of selected students at a state and a privately supported dental school, classified dental students into four groups: (1) the instrumentalists were those who viewed their patient and the practice of dentistry as a means to gain a higher standard of living and experience the good life; (2) the technicians were those who viewed their patients as a showcase for the exhibition of their technical skills; (3) the humanitarians were those who viewed the profession as a means to help people with their oral health problems; and the (4) scientists and scholars were those who were interested essentially in the oral knowledge, toward which the patient could contribute.

$\mathrm{Jaco}^{54}$ used this classification in his evaluation of the views of dental students before and after their participation in a program for the chronically ill and aged at their homes. He noted that humanitarians and scientist-scholars rated considerably higher in their interest and performance for the shut-in patients than did the technicians and instrumentalists, who comprised 78 percent of the group of senior dental students studied.

Borland and Hardyck ${ }^{15}$ studied the attitudes of junior dental students before and after a series of one-hour lectures in psychology. Although the two investigators state that their findings are tentative, they report that students were more competent in meeting the interpersonal problems of providing treatment after they had completed the new course of studies.

Podshadley and Chen ${ }^{92}$ similarily, report ability to alter the attitudes of dental students toward public health practices in a relatively short period of time.

Smith $^{166}$ concludes his review of the literature of the attitudes and motivation of dental students by stating that a change in attitudes toward public health can be made and observed under certain conditions. Specifically he calls attention to Jaco's 54 finding of the variation in the effect of a community health experience that is a function of a student's personality characteristics. Smith speculates that increased time for courses in public health may not be necessary to change the attitudes of students because a variation in the educational opportunities and experiences may be all that is necessary to reach students of different persuasions.

From the reports of the writers reviewed it seems that resocialization, the abandonment of one's style of life for a new style that not only is different but incompatible with the old style. ${ }^{112}$ may be realized readily and become permanent in nature. These findings do not seem to fit the pattern that one might expect from the type of applicant for the course in dentistry, the rigorous admission policies enforced, and the pattern of student-faculty relationships that have been described.

The findings of other writers seem to contradict the reports just presented. For example, Grusky et al., ${ }^{43}$ reporting their evaluation of attempts to develop a curriculum in social sciences found the response of students generally negative. They conclude that introduction of courses on social science in the curriculum of a dental school is difficult because it competes for both time and interest of a student whose main concern is to develop the technical skills of dentistry.

O'Shea et al. $^{88}$ raises a question on the reliability of students' replies when sociological perspective is required. Answers may be secured that represent those which the investigator would like to hear. Pelton ${ }^{90}$ warns in his remarks, during a seminar convened to consider departments of social dentistry, that a course or two in public health will not overcome the tendency of dental schools to train students to provide care for an exclusive clientele of private-paying patients.

Blackerby ${ }^{11}$ reported at the same meeting, that less than two percent of the total curricular hours during the four years of dental education, as reported in the 1961-63 catalogs of 44 of the 47 schools of dentistry in this country, was devoted to courses that could be accepted as the logical content of departments of social dentistry. 
Striffler ${ }^{122}$ reinforces this statement by concluding that a long time will be required before the traditional departments of schools of dentistry become willing to release curricular hours to vague concepts of training students to become socially sensitive dental practitioners.

The purpose in presenting these differing opinions from the literature, has been to examine some of the fundamental problems found first in developing the socially sensitive practitioner, and secondly, in measuring the results of these efforts. The usual clinical departments of restorative dentistry, the various forms of prosthetic dentistry, endodontics, orthodontics, and periodontics have established a precise pattern of technic to determine the competence of students as future practitioners. The departments of social dentistry have much more vague and indirect measures of students' competence in social sensitivity, not to mention practitioners' competence.

Since at the present, the development of precise indexes for the measurement of competence in social sensitivity of students seems to be an accomplishment for the future, an approach might be tried first to measure the view of community dentistry held by the total faculty of each school.

Professionalization is essentially an effort to encourage the adoption of the ideals universally accepted in today's culture; the ethical standard, personal integrity, an appreciation of dignity, an acute sense of responsibility, a dedication to service, an appreciation of vocational accomplishments, and a scholarly inclination. ${ }^{29} \mathrm{It}$, in short, is the development of a "professional Self." One of the most important aspects of an individual's development of such a concept is derived from his view of the reactions of others to him, particularly those reactions that come from significant situations. Each dentist grows, develops, and eventually matures within the context of many different publics. ${ }^{81}$

The significant public for the dental student is the faculty. For a period of years the student has to await transition from the school to active practice by himself. His public, important to him, because it shapes him and his image of himself by its judgments and reactions to him constantly has been the faculty member--a professional dentist. His social sensitivity will, in many ways, naturally be a reflection of the faculty member and their relationships. ${ }^{29}$

The review reported of the trends detected in the literature reviewed would seem to discount a high potential for competence in social sensitivity on the part of the graduating student. The rigid criteria for admission, the hostile atmosphere in the student faculty training situation, the limited time made available to the department of social dentistry, and the constraints of the number-system of clinical grading-all precise measurements-are discouraging potential competency in social sensitivity. Social sensitivity appears as a product that will result from innovations in the curriculums of dental schools. When these innovations are accomplished optionally, the occupational socialization of the dental student will become a truly professional socialization. No measurements of social sensitivity then will be needed. Bc reminded constantly ${ }^{4}$ that the dentist has a right to win for himself those things which give him and his family the ability to take a proper place in the community that he serves, but that no alternative is going to be found by professional people for placing service to the public first.

\section{Bibliography}

1. Admission requirements of American dental schools; 1968-69. Chicago, American Association of Dental Schools, 1968. 148p. (p. 8)

2. Idem.. p. 13.

3. American Dental Assuciation testing program: 1968-70. Chicago. American Dental Association, 1968. 21 p.

4. Principles of ethics. Rev.. Chicigo, American Dental Association, 1958. 4p. 
5. Bahl, John. Are the goals and objectives of the report reasonable? p. 20-22. (In report of the Committee on Curriculum Control of courses in dental public health and preventive dentistry. J. Dent. Educ., 22:322-8, Sept. 1958.)

6. Becker, H.S., et al. Boys in white: student structure. Chicago University Press, 1961. 456p.

7. Becker, H.S., and Greer, Blanche. The fate of idealism in medical schools. Am. Sociol., Rev., 28:50-56, Winter 1958.

8. Becker, H.S. Personality change in adult life. Sociometry, 27:40-53, Mar. 1964.

9. Blackerby, P.E., Jr. Why not a department of social dentistry. J. Dent. Educ., 24:197-200, Sept. 1960.

10. - Rationale for a department of social dentistry. J. Dent. Educ., 27:119-23, June 1963.

11. _.... Departments of social dentistry: a review. p. 47. (In Social Dentistry Seminar proceedings. Apr. 1963. Kellyton Alabama. Birmingham, Ala., University of Alabama, 1963. 83 p.)

12. Bloom, S.W. The process of becoming a physician. Ann. Am. Acad. Political and Social Science, 346:77-87, Mar. 1963.

13. ㄴ.. The sociology of medical education. Milbank Memorial Quar., 43:143-84, Apr. 1965.

14. Bohannan, Harry. The dental admissions policy. Ky. Dent. J., 14:159-68, July 1962.

15. Borland, L.R., and Hardyck, C.D. Psychology in the dental curriculum-a study of the effectiveness in modifying attitudes and values. J. Dent. Educ., 24:71-7, Mar. 1960.

16. Calisti, L.J., and Kramer, B.M. Dental public health for dental students: review and philosophy. J. Dent. Educ., 29:85-9, Mar. 1965.

17. Caplovitz, David. Student-faculty relations in medical school: a study of preprofessional socialization. New York, Columbia University, 1961. unpublished thesis.

18. Chen, Martin, et al. A fractional study of some psychological, vocational interest and mental ability variables as predictors of success in dental school. J. Applied Psych., 51:236-41, June 1967.

19. Clark, H.T. A challenge to American dentistry. J. Dent. Educ., 28:381-7, Dec. 1964.

20. Counsell, L.A. The intraprofessional image of dentistry. J. Pub. Health Dent., 28:35-48, Winter 1968.

21. Crowder, Truman. The dental student, and social responsibility: a review of the literature, p. 31-42. (In Report of dental education; summer internship paper for graduate education and psychology students. Chicago, American Association of Dental Schools, 1966. 235p.)

22. Douglas, B.L. Preventive and social dentistry. J. Dent. Educ., 28:126-30, June 1964.

23. Douglass, C.W. Social sciences in the dental curriculum. Ann Arbor, University of Michigan, Dec. 1967. 33p. + bibliog mimeographed.

24. Dunning, J.M. Ecological dentistry. Harvard Dent. Alumni Bul., 25:24-6, Fall 1965.

25. Durocher, R.T., ed. Kentucky Conference on Dental Curriculum. J. Dent. Educ., 26:301-488, Dec. 1962. (p.374)

26. Etzioni. Amitai. Interpersonal and structural factors in the study of mental hospitals. Psychiatry, 23:13-22, Feb. 1960.

27. Evans, R.I. Social and behavioral sciences research: 1962-1966. Am. Dent. A. J., 74:1500-11, June 1967.

28. Fernandez-Pabon, Jorge. Prediction of success in dental school on the basis of dental aptitude score and other variables. J. Dent. Educ., 32:261-71, Sept. 1968.

29. Fisher, A.K. The indoctrination of dental students with a professional attitude. J. Dent. Educ., 24:38-41, Mar. 1960.

30. Fortenberry, Marshall. Our community responsibility. Am. Col. Dent. J., 34:246-8, Oct. 1967.

31. Forrest, E.J. Some criteria for the selection of students for dental school. J. Dent. Educ., 25:208-12, Sept. 1961.

32. Friedrick, Rudolph. Three year study of preprofessional education, student recruitment and admission policies. J. Dent. Educ., 29:387-96, Dec. 1965.

33. Fredericks, M.A., and Mundy, Paul. Dental students: social background and attitudes. Am. Col. Dent. J., 34:159-67, July 1967.

34. _... Relationship between social class, average grade in college, D.A.T. score and academic achievement of dental students. J. Dent. Educ., 32:26-36, Mar. 1968.

35. From, L.D. The effects of medical education on medical student attitudes. J. Med. Educ., 30:559.66, Oct. 1955.

36. - . The effects of medical education on medical student attitudes: a follow up study, Part II. J. Mcd. Educ., 33:25-33, Oct. 1958.

37. Giddon, D.B., and Dunning, J.M. "Ecological Dentistry"-as a term to indicate dental public health, practice management, and social sciences. J. Dent. Educ., 27:81-3, Mar. 1963.

38. Ginley, Thomas. Present status and future plans of the dental aptitude testing program. J. Dent. Educ., 30:163-74, June 1966.

39. Gleison, J.C., et al. Developing a teaching program in community dentistry. An approach to liberalizing the dental curriculum. J. Dent. Educ,, 28:174-84, June 1964. 
40. Gray, Shirlene. Image of dentistry, medicine and teaching as seen by high school students. 11. Effect if occupational values and ideal job characteristics. J. Dent. Educ., 31:195-206, June 1967.

41. Gross, Neal, et al. Explorations in role analysis: studies of school superintendency role. New York, Wilcy, 1958. IXV 379p.

42. Gruebbel. A.O. Objectives of a course in public health dentistry. J. Dent. Educ., 20:114-18, Mar. 1956.

43. Grusky, oscar, it al. Effect of a social science curriculum on attitudes of freshman dental students. An. Dent. A.J., 74:769.77, Mar. 1967.

44. Guild, A.D. Teaching methods in community and preventive dentistry program. Paper presented at Kentucky conference on preventive dentistry. Lexington, Ky. Apr. 1967. 20 p. mimeographed.

45. Hadjimarkins. D.M. Teaching public health to dental students. Am. J. Pub. Health, 44:1352.6, Oct. 1954.

46. Hein, J.W. Administration problems and their possible solution. p. 12-21. (In Social Dentistry Seminar proceedings, April 11-12, 1963. Kellyton, Ala., University of Alabama, 1963. 81 p.)

47. Heist, Paul. Personality characteristics of dental students. Educ. Rec., 41:240-2, July 1960.

48. …. The study in education for the professions. p. 211-36. (In Nelson, B.H., ed. The 61st yearbook of the National Society for the Study of Education. Chicago, National Society for the Study of Education, 1962. XI $312+$ CVII p.)

49. Heller, D.B. et al. Selection of students for dental schrol. I. Dent. Educ, 29:202-7, June 1965.

50. Henry, Juseph. The charge to the graduating class of 1968. Am. Col. Dent. J. 290-2, July 1968.

51. Hill, Thomas. The objective's of the dentist in his community. Am. Dent. A.J., 60:327-9, Mar. 1960.

52. Horowitz. M.J. Educating tomorrow's doctors. New York, Appleton-Century-Crafts, 1964. XV $264 \mathrm{p}$.

5.3. Ireland, R.L. The plaming requirements to establish a chair of social dentistry. J. Dent. Educ., 24:209.13. Sept. 1960.

54. Jaco, E.C. Evaluation of teaching in chronic illness and the handicapped in dental education. J. Health and Human Behavior. 6:35-48, Sept. 1965.

55. Kegeles, S.S. The place of behavioral science in dental public health. Dent. Clin. No. Am., p. 697-707, Nov. 1962.

56. Kirk, Barbara, et al. Personal and vocational characteristics of dental students. J. Personnel and Guidance. 41:522-7. Nov. 1963.

57. Knapp, R.M. Preventive dentistry programs in dental school. J. Dent. Educ., 28:26-30, Mar. 1964.

58. Knutson, I,W. Summary of the New Brunswick Workshop on the Teaching of Dental Public Health. J. Dent. Educ., 29:107-8, Mar. 1965.

59. Kreit, Leonard, and MacDonald, Ralph. Preprofessional grades and the dental aptitude test as predictors of student performance in dental school. J. Dent. Educ., 32:45 7, Dec. 1968.

60. Kutner. Bermard. and Jaffe, P.E. Dentistry and the behavioral sciences: the convergence of disciplines. J. Dent. Educ., 27:22-4, Mar. 1963.

61. Levinson, D.J. Medical education and the theory of adult sucialization. J. Health and Human Bchavior, 8:253-65, Dec. 1963.

62. Linton, Ratph. The study of man. New York, Appleton-Century, 1945. VIll + 503p. (p. 105)

6.3. .... . The cultural background of personality. Now York, Appleton-Century, 1945. XII + 102p. ip. 77)

64. Lotzkar. Stanley. The demography of teaching programs for preventive dentistry and com. munity health. Paper presented at Kentucky progtam for preventive dentistry and community health. lexington. Ky., Apr. 1967. 14p. mimeographed.

65. Lucas. R.J.. and Young, W.O. Community laboratory experience for dental education. I. Dent. Educ. 31:77.83, Mar. 1963.

66. Lucas, R.J., and Shrock, J.G. Identifying socially sensitive applicants for dental schools. J. Pub. Heith Dent. 29:92.5, Spring, 1969.

67. Manhold. John, at al. Comparison of interests, needs and selected personality factors of dental and medical students. Am. Dent. A.J., 67:601-8, Oct. 1963.

68. Manhold, John, and Manhold, Beatrice. Final report of an 8 year study of the D.A.T. in predicting 4 year performance in a new dental school. J. Dent. Educ., 29:41-5, Mar. 1965.

69. -.... Predictor value for 4 year performance of individual parts of the D.A.T. J. Dent. Educ., 31: 62.70, Mar. 1967.

70. Mann, W.R. Dental education p. 239-422. (In Hollinshead, B.S., dir. The Survey of Dentistry; the final report. Washington, Am. Council on Education, c1961. XXXIV + 603p. 
71. Mann, W.R., and Parkin, Grace. The dental student applicant. J. Dent. Educ., 24:16-30, Mar. 1960.

72. Merton, R.K., et al. The student physician. Cambridge, Mass., Harvard University Press, 1967. $306 \mathrm{p}$.

73. Miller, G.E. Teaching and learning in medical school. Cambridge, Mass. Harvard University Press. 1961. 304p.

74. Moosbrucker, Jane, and Giddon, Donald. The effect of experience with aged, chronically ill and handicapped patients on student attitudes. J. Dent. Educ., 30:278-86, Sept. 1966.

75. More, D.M. The dental student. Am. Col. Dent. J., 28:1-93, Mar. 1961.

76. More, D.M., and Kohn, Nathan, Jr. Some motives for entering dentistry. Am. J. Sociol., 66:48-53, July 1960.

77. More, D.M. A qualitative summary of student reasons to enter dentistry. J. Dent. Educ.. 25:45-50, Mar. 1961.

78. - Attitudes associated with dental schools. Am. Col, Dent. J., 29:140-64, Scpt. 1962.

79. _..... Background characteristics. J. Dental Educ., 28:11-14, Mar. 1964.

80. … Motives for occupational commitment. Am. Col. Dent. J., 29:128-39, Sept. 1962.

81. _..... The dental student approaching graduation; 1962. Am. Col. Dent. J., 29:115-208, Sept. 1962.

82. Morris, Alvin. Educational needs of the dental student in dental public health: view of the dental school. J. Dent. Educ., 29:93-8, Mar. 1965.

83. Nedelsky, Leo. The dental curriculum of tomorrow. J. Dent. Educ., 31:33441, Sept. 1967.

84. Needham, Peter. Dental student-special patient program at the University of Missouri in Kansas City, J. Dent. Educ, 28:2945, Sept. 1964.

85. Newcomb. T.M. Social psychology. New York, Drydent Press, 1951. XI +690p. (p. 280)

86. ﹎.... Personality and social change; attitude formation in a student community. New York, Dryden Press, 1943.25 p.

87. Nikiforuck, Gordon, and Kreutzer, Jack. Preventive dentistry; an integral part of the dental curriculum. J. Dent. Educ., 23:238-43, Dec. 1959.

88. O'Shca, R.M., et al. Sociologic perspective on the dental student. J. Dent. Educ., 30:311-17, Sept. 1966.

89. Pelton, W.J. Teaching "Social Dentistry." Am. Col. Dent. J., 31:196-8, Oct. 1964.

90. …_. Introduction p. 24 (In Social Dentistry, Seminar proceedings. April 11-12, 1963, Kellyton, Alabama. Birmingham, University of Alabama, 1963. 81p.)

91. Phipps, Grant, et al. Prediction of success in a dental school. J. Dent. Educ., 32:161-7, June 1968.

92. Podshadley, D.W., and Chen, Martin. An exploration of dental student attitudes toward public health in relation to personality attitudes. Preventive dentistry and community health. U.S. Government Printing Office, Washington, 1966. A 38 and B $27 \mathrm{p}$

93. Podshadley, D.W., et al. Introduction to dental public health. P.H.S. Publication No. 1134. Washington, Government Printing Office, 1964. VII $+183 p$.

94. Podshadley, D.W. Programmed instruction: highlights of its use in teaching public health. Am. J. Pub. Health, 55:887-91, June 1965.

95. Pollack, Burton. An attempt to catalogue and compare the teaching and program objectives for courses in preventive dentistry and community health in 9 dental schools. Paper presented at the Development Conference for Preventive Dentistry and Community Health. Kellyton, Alabama, Oct. 19-21, 1966. 9p. mimeographed.

96. Povalko, Ronald. Social background, and occupational perspectives of predental students. J. Dent. Educ., 28:253-59, Sept. 1964.

97. Quarantelli, E.L. Attitudes of students toward specialization and research. Am. Col. Dent. J. 27:100-7, June 1960 .

98. ….. The carcer choice pattern of dental students. J. Health and Human Behavior, 2:124-32, Summer 1962.

99. - The dental student image of the dentist paticnt relationship. Am. J. Pub. Health, $51: 1312-19$, Sept. 1961

100. Ramirez, Albert, et al. Use of smulated experience in teaching community dentistry. J. Dent. Educ, 31:521-27, Dec. 1967.

101. Ratcliff, P.A., and Oliver, G.V. Learning experience and content in dental education. J. Dent. Educ., 88:282-7, Sept. 1964.

102. Richards, Louise, and Lefcowitz, Myron. Interest in dentistry: a pilot study of high school students. II. Effects of occupational values and ideas of job characteristics. J. Dent. Educ., 31:195-206, June 1967.

103. Richards, N.D. Social sciences and dentistry: a sociological appraisal. Internat. Dent. J., 17:86.92, Mar. 1967.

104. …. Sociological studies in the field of dentistry. Brit. Dent. J., 119:179-83, Sept. 7. 1965 
105. Robinson. H.B.G. A department of social dentistry. Implications to public health practice. J. Dent. Educ., 24:205-8, Sept. 1960.

106. Ross, M.c;. The contributions of social and behavioral sciences to the health sciences. J. Dent. Research, 44:110411. Nov.-Dec. 1965.

107. Ross. Norton. Dental aptitude test results, college grades, as predictors of success in a school of dentistry. J. Dent. Educ., 31:84-8, Mar. 1967.

108. Russel, C.H. Liberal education and dentistry. Educ. Rec., 41:40-66, Jan. 1960.

109. Sanders, Edith R. Current status of departments of social dentistry. J. Dent. Educ., 30:354-8, Dec. 1966.

110. _._. Socially sensitive dentists for a changing society. The approach of one school. J. Pub. Health Dent., 28:27-31, Winter 1968.

111. Sargent, S.S. Concepts of rolc and ego in contemporary psychology. p. 355-70. (In Rohrer, Jobn. and Sherif. Muzafer, eds. Social Psychology at the cross roads. New York, Harper and Brothers, 1951. V111 + 437p.) (p. 139$)$

112. Solznick, (rertrude J. Socialization. p. 84-109. (In Brown, Leonard, and Selznick, Philip. Sociolngy. New York, Harper and Row, 1968. Xlll +562p.)

113. Sheldon, Marvin. A step in developing a department of social dentistry. J. Dent. Educ., 25:318-21. Dec. 1961.

114. Shcldon, Marvin, and Henry, Joseph. Teaching dental care for chronically ill and aged patients. J. Dent. Educ., 29:245-8, Sept. 1965.

115. Shuval. J.T. Methods of assessing public attitudes to health. Internat. Dent. J., 17:63-74, Mar. 1967.

116. Smith, L.V. Attitudes and motivation of dental students related to the teaching of dental public health. J. Pub. Health Dent., 26: 246-55, Spring 1966.

117. Stanford. Nevitt. Higher cducation as a field of study. p. 31.73 (In Stanford, Nevitt, ed. The American college. New York, Wiley and Son, 1967. XIV + 1084p.)

118. __ Development status of the freshman. p. 253-89 (Stanford, Nevitt, ed., The American College. New York, Wiley and Sons, 1967. XVI + 1084p.)

119. Stiles. W.W., et al. Preventive medicine and public health in the dental curriculum. J. Dent. Educ., 20: 169-76, May 1956.

120. Strachin, [D.S. Persunal communication, 1968.

121. Striffler, D.F. The integration of a course in practice administration in a department of community dentistry. p. 13-20. (In Proceedings of the Conference on the Teaching of Dental Practice Administration. Ann Arbor, University of Mich., W.K. Kellogg Foundation Institute, 1963. 104p.)

122. W_ Teaching problems and methods. p. 22-38. (ln Social Dentistry Seminar proceedings, April 11-12, 1963. Kellyton, Alabama. Birmingham, University of Alabama, 1963. 81p.)

123. Tossas, Alberto. Teaching social dentistry; one school's approach to a 4 year integrated program. J. Dent. Educ., 31:352-9, Sept. 1967.

124. Upshaw, H.S. Psychological testing for the selection of dental students as a measure of improving nontechnical aspects of dentistry. J. Dent. Educ., 24:328-32. Dec. 1960.

125. Waldman, H.B. Teaching a new phase in dental care. Western Reserve Univ. Sch. Dent. Alumni Bul., 7:8.10, May 1965.

126. Walsh, John. Dentistry and the social sciences: the profession's responsibility. Internat. Dent. J., 17:75-82, Mar. 1967.

127. Webbs, Sam. The prediction of achievement of the 1 st ycar dental student. Educ. and Psych. Measures. 16:543-48, Winter 1956.

128. Weiss, R.1. Teaching dental public health-a curriculum for undergraduate students. J. Pub. Health Dent., 15:1-11, Jan. 1956.

129. Western Reserve University, Division of Preventive Dent. and Community Health; formerly directed by this writcr.

130. Young, Wesley, and Zwemer, T.J. Objectives and methods of teaching preventive dentistry and community health. J. Dent. Educ., 31:162-7. June 1967.

131. Young. W.O. Methodology for teaching preventive dentistry and community health. Paper presented at Development Conference for Preventive Dentistry and Community Health. Kellyton, Alabama, Oct. 18-21, 1966. 13p. mimeographed.

132. _ The developmene and administration of a community dental program. Am. Col. Dent. J., 34:161-9, Dec. 1967.

133. Zwemer, T.J., et al. Six steps to better dental education. J. Dent. Educ., 32:185-7, June 1968. 